\title{
Facing climate risk management together in Colombia
}

\begin{tabular}{|c|c|}
\hline $\begin{array}{l}\text { With climate change altering the } \\
\text { short-term weather and causing } \\
\text { long-term climatic fluctuations, } \\
\text { farming communities are } \\
\text { becoming increasingly } \\
\text { susceptible to climatic risk. } \\
\text { However, with the help of the } \\
\text { CGIAR Research Program on } \\
\text { Climate Change, Agriculture } \\
\text { and Food Security (CCAFS), } \\
\text { a participatory approach is } \\
\text { being taken to climate risk } \\
\text { management. As a result of } \\
\text { south-south collaboration, } \\
\text { Local Teehnical Agro-climatic } \\
\text { Committees (LTACs) have been } \\
\text { established in local communities } \\
\text { that enable farmers to make } \\
\text { decisions based on knowledge } \\
\text { of how local weather will affect } \\
\text { their agricultural production. } \\
\text { This has huge implications } \\
\text { on local and international } \\
\text { food security, and it is already } \\
\text { becoming a necessity. }\end{array}$ & $\begin{array}{l}\text { gricultural communities are very } \\
\text { sensitive to changes in both } \\
\text { weather and climate, as } \\
\text { significant changes can cause entire } \\
\text { crop seasons to fail, triggering large } \\
\text { alterations to income, as well as } \\
\text { endangering local and international } \\
\text { food security. Farmers face uncertainty } \\
\text { in weather patterns over the short tern } \\
\text { and climate over the long term; more } \\
\text { than one-third of agricultural yield } \\
\text { variation globally is a result tof variatior } \\
\text { in climate and weather. If farmers are } \\
\text { to manage their crops well in the face } \\
\text { climate change, they will need to knov } \\
\text { how changes to weather and climate it } \\
\text { their local region will affect their ability } \\
\text { to successfully grow crops. } \\
\text { The traditional issue that farmers face } \\
\text { is that they do not know what weather } \\
\text { conditions or changes in climate their } \\
\text { crops will be subject to once planted, } \\
\text { leaving them vulnerable to significant } \\
\text { change, which increases the risk of } \\
\text { crop loss and can affect food security } \\
\text { and the quality of life amongst } \\
\text { farming populations. }\end{array}$ \\
\hline
\end{tabular}

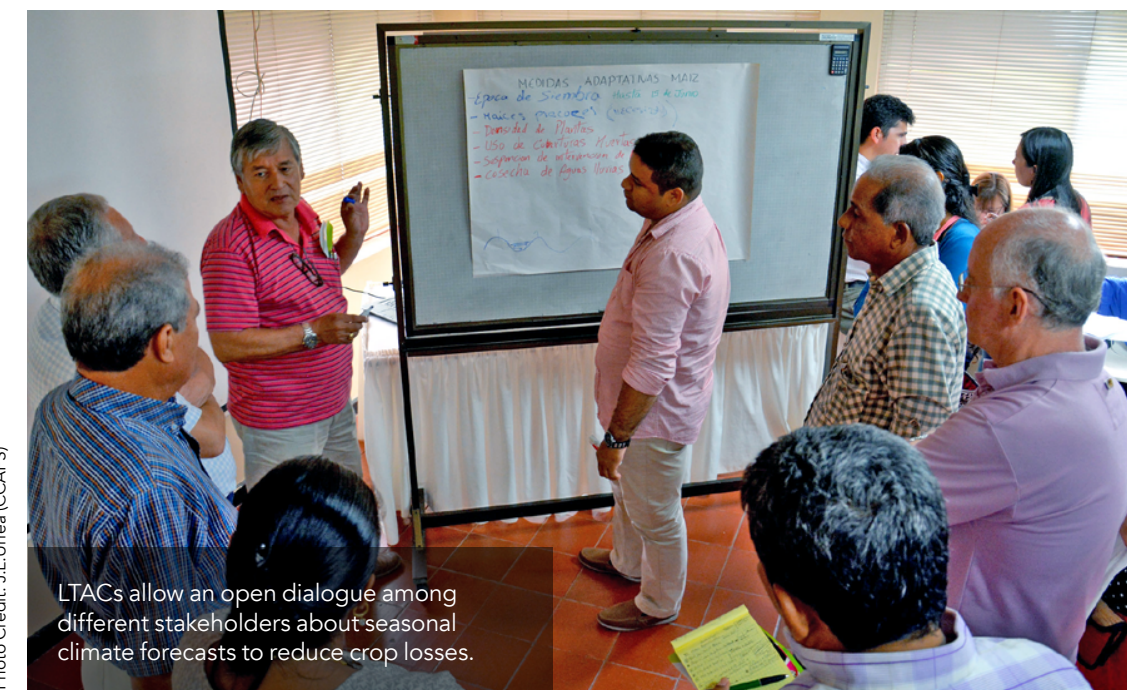

However, with marked advances
in climate science, as a result of in climate science, as a result of possible to predict changes in weather and climate with a certain degree of confidence. Combined with crop models that have improved to the crops will fare under a range of climate conditions, farmers are now able to evaluate how to grow crops based on likely climate conditions. In order to be relevant climate predictions should address local conditions so that farmers can make effective decisions about issues such as fertilizer and planting dates, employing climate risk management.

To make best use of this technology, the CGIAR Research Program on Climate Change, Agriculture and Food Security (CCAFS) has developed and promoted a system of Local Technical Agro-climatic Committees (LACS). These are groups can make that come together so that they to manage their farms and businesses with the help of individuals from state organisations and other local agencies, using climate prediction technology. This initiative is carried out with support from the CGIAR Trust Fund and through bilateral funding agreements and worked on by individuals such as $\mathrm{Dr}$ . esearch at CCAFS and leader of the With significant experience in leadership on partnerships and capacity for scaling limate-smart agriculture, she is perfectly placed to contribute to this w

HOW DO LTACS WORK?

LTACs are groups that come togethe

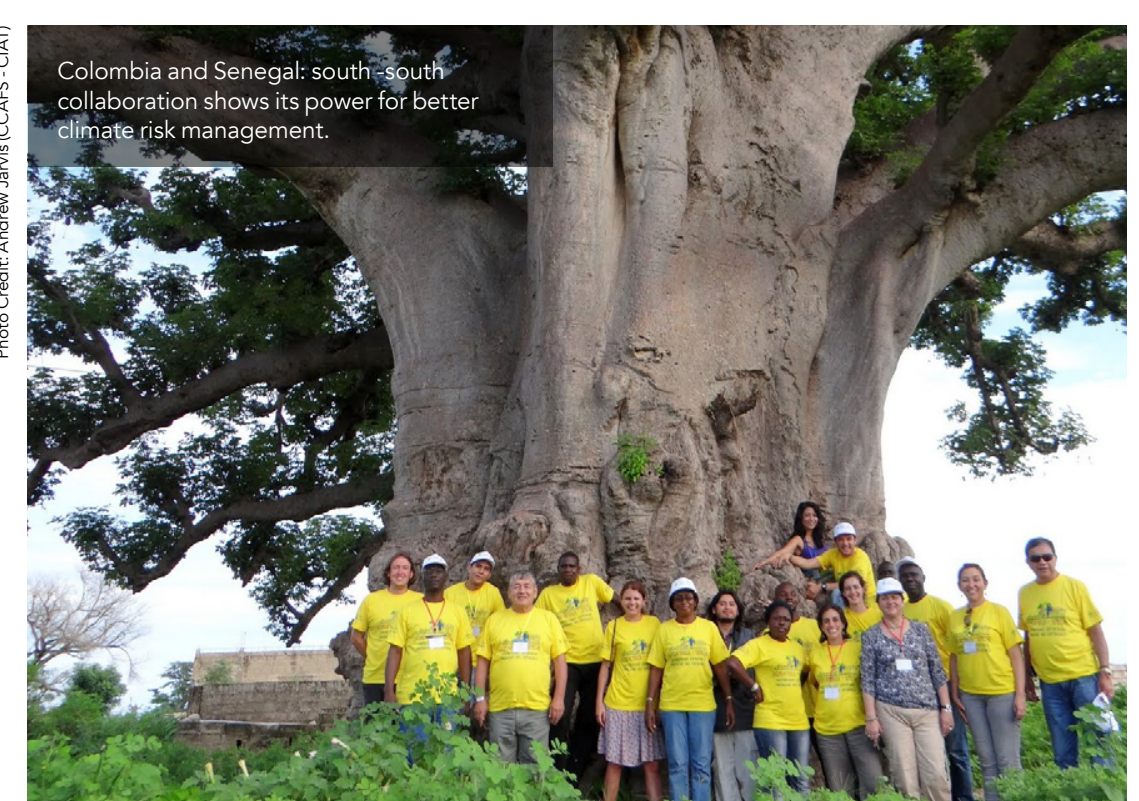

forecasts, created by local and nationa gricultural sector instiutions and specific information. The basic idea of the LTACs is that if farmers can access and understand locally relevant weather and climate forecasts, and how their crops will respond to these, they can make better decisions on how to manage their farms. LTACs rely on promoting dialogue among scientists, technicians, the private sector, decision makers and farmers to design and implement effective action to reduce agro-climatic risk. LTACs adop a participatory approach - a basic premise of the process is that knowledge-intensi practices require learning through Interaction and shared understandings the climate forecasts and help devise measures to reduce crop losses.

While CCAFS initially provided technical support to the committees by assisting with their organisation, training and development of methods, LTACs have grown as a result of capacity building within local and national institutions, guaranteeing their stability and sustainability. CCAFS is no longer involved in the committees as the capacity has been built, both in local and national institutions. Notably, capacity at national level guarantees the sustainabilly of the initiative over time. LTACs are places for dialogue between diverse local actors. As such, each committee is different, and will come to their own
These committees have become sources local levels are the key stakeholders.

\section{HOW AND WHERE}

In 2013, CCAFS established a Climate Smart Village (a village in which local decisions are made about how the community should adapt to climate change) in Cauca, Colombia, toge organisation, Fundación EcoHabit While this was being established, CCAFS also identified an existing

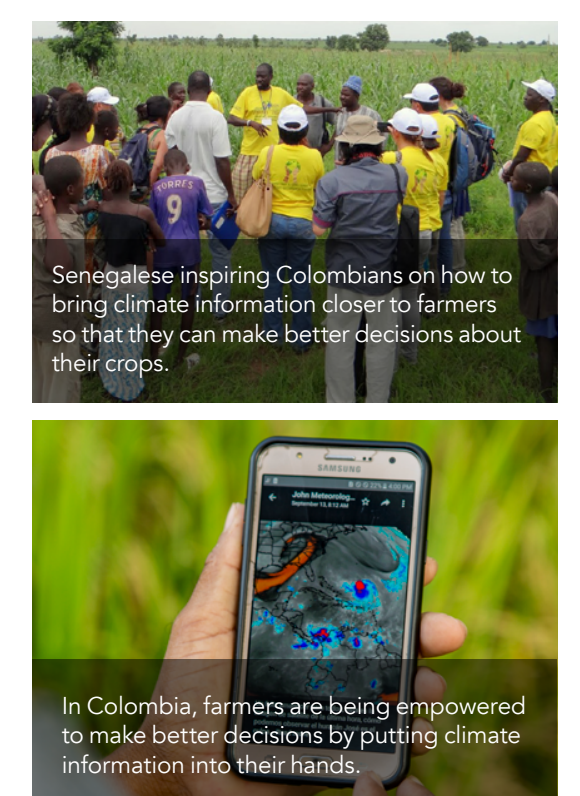

CCAFS and the International Centre for Tropical Agriculture (CIAT) to mitigate the effects of climate change and climate variability in the country. As part of this initiative, an interchange was in Senegal. The aims of the senegalese programme were to empower farmers to make better decisions by putting climate information in their hands.

Subsequently, CCAFS invited a senegalese delegation to Colombia to share experiences, where they then met with local and nationa

$38 \%$ of farmers in the region indicated that they had increased yields and reduced losses as a result of the LTAC's activities.

and indigenous groups to variations in weather. Together, these schemes brought together local town and associations, community action groups, and leaders of indigenous communities, and integrated them into a Participato Agro-climatic Early Warning System climatic conditions and the use of good environmental practices for water and associated risk.

Simultaneously, in 2013, the Colombian Government, through the Ministry of Agriculture and Rural Development and farmers associations. There was such a positive reaction to this meeting that it was decided that an initiative would be developed that would enable farmers to make decisions based on relevant information. After the visit of the senegalese delegation and the political support from the MADR, CCAF organised an informal meeting with multiple agencies to promote the initiative, which eventually led to the establishment of two LTACs (one in Cauca and another in Cordoba). MADR, CIAT, and the Turipaná Regiona Center of the Colombian Corporation in Agricultural Research were 


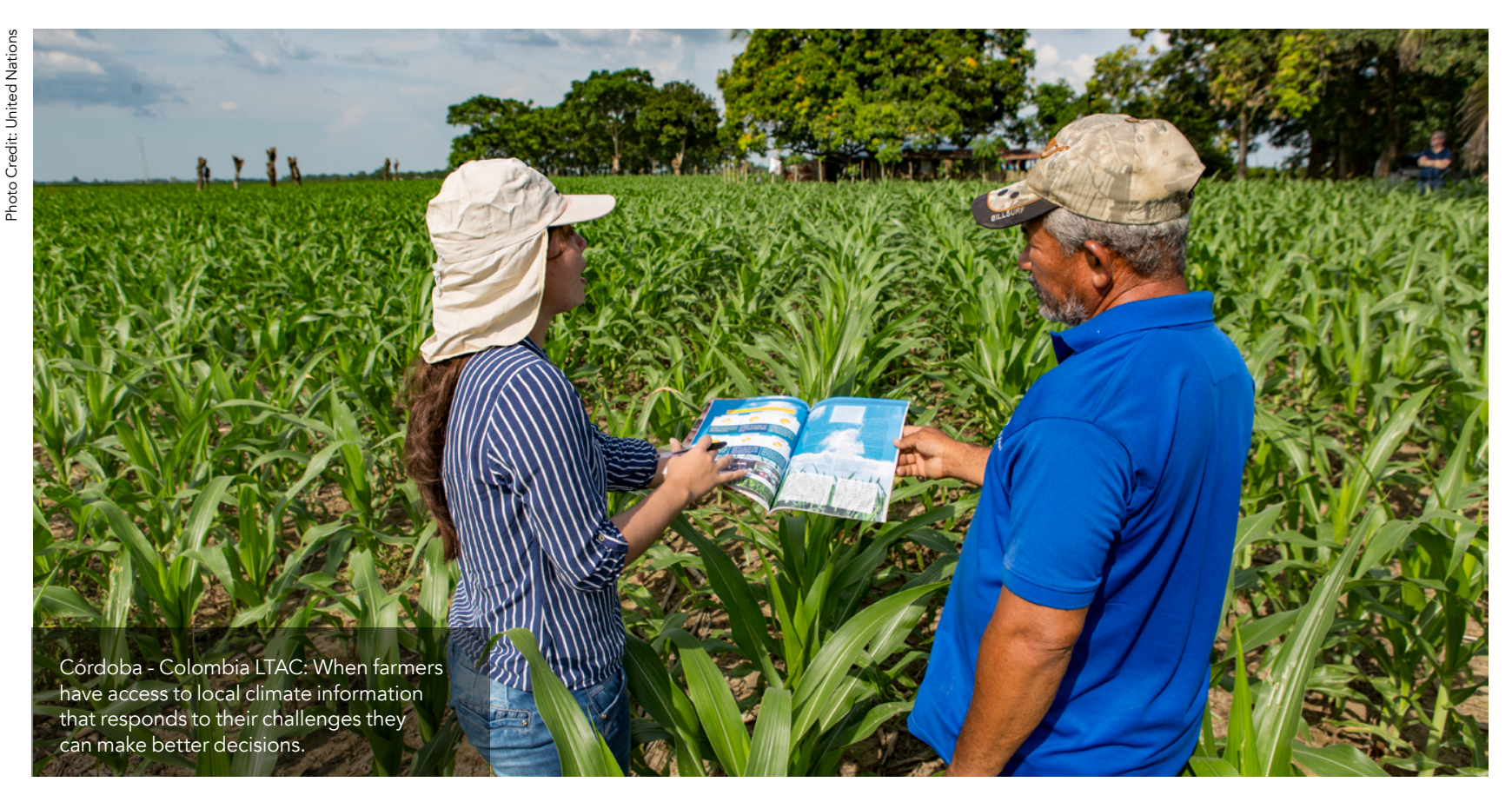

\section{THE SUCCESSES}

The LTACs have had significant result of government agencies and communities actively participating LTACs, communities have been able to confidently plan with more reliable information on agro-climatic forecasts There has been improved articulation between organisations, more agreements based on trust, freer interchange of ideas and communication, and greater capacity to use knowledge. In 2015 for example, the Cauca LTAC met 12 times, and base on the occurrence of an El Niño even (a meteorological event that causes rainfall levels to decrease in Colombia), a model was used to assess the likely in the region. A plan was collectively decided upon, and farmers adopted a number of strategies to guarantee water supply, which included protecting rivers and streams and planning alternative planting dates to avoid the worst of the drought. After this process, $38 \%$ of farmers in the region indicated that they had increased yields and reduced losses as a result of the LTAC's activities.

This example is one of many; it is evident that farmers and rural communities can make better decisions if they have access to local climate information that directy responds to their challenges so that they can take grounded actions based on evidence that they themselves can
see. The successes of LTACs show that
It is evident that farmers and rural communities can make better decisions if they have access to local climate information.

it is essential to promote conversations Senegal and Colombia. Through this between scientists, technicians, the private sector, decision makers and farmers to implement effective actions to reduce the risk of agricultural sectors to the climate.

Given the success of the LTACs, and the urgency required to address agroclimatic risks, especially at the local level, the Government of Colombia Determined Contribution (which is a cotenmitment in front of the interna community) the establishment of at least 15 LTACs as a measure to promote to climate change and variability. This speaks to the effectiveness of LTACs; in Colombia. Given that agriculture represents $6.3 \%$ of the country's GDP, this
is an important step. The involvement is an important step. The involvement of national government institutions is key
to guaranteeing sustainability and scaling of this type of approach.

\section{THE FUTURE OF LTACS}

south colia the result of a southfood security and enhance adaptation they have successfully informed policy

The process of establishing LTACs collaboration, LTACs have now been intlated or developed in other coun in Latin America in seven countries, which have been implemented through the leadership of local and national organisations with support from CCAFS.

In time, it is expected that more communities will adopt the LTAC approach, given the success that it is provide technical input to the countries that are implementing the approach, but they are also in the process of creating a 'Manual for the Establishment of LTACs', for implementing the approach.

The manual divides the approach into seven clear and logical steps that are carried out with participating institutions. Each step is based on what was covered in the previous steps. This is excellen news for agricultural communities who are on the front line of climate change, and could have a huge impact on international food Nicaragua. There are now 31 LTACS which will provide step-by-step guidelines

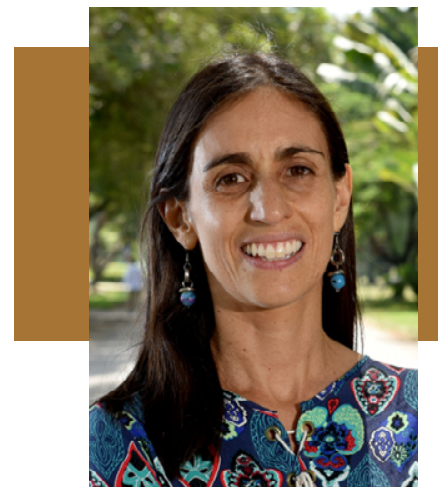

Behind the Research Dr Ana Maria Loboguerrero

Research Objectives

The Local Technical Agro-climatic Committees (LTAC) are tool for farmers to understand, use and benefit from agro-

\section{Detail}

Km 17, Recta Cali-Palmira Cali, Colombia

Bio

Dr Loboguerrero is Head of Global Policy Research at

CCAFS. In this position she plays a major role in leadership Agriculture. Dr Loboguerrero also leads the CCAFS Latin American Regional Program. Ana Maria holds a PhD on Economics from University of California, Los Angeles (UCLA).

Funding

Pris work was implemented as part of the CGIAR Research Program on Climate Change, Agriculture and Food Security (CCAFS), which is carried out with support from the CGIAR Trust Fund and through bilateral funding agreements. For details, please visit https://ccats.cgiar.org/donors. The views official opinions of these organisations.

\section{Collaborators}

We would like to acknowledge co-authors of the paper, Bridging the gap between climate science and tanters in Colombia. Francisco Boshell, Gloria León, Deissy Martinez-Baron, Diana
Giraldo, Liliana Recaman Mejia, Eliecer Díaz and James Cock. The Ministry of Agriculture and Rural Development of Colombia, International Center for Tropical Agriculture (CIAT) Agricultural Research (CORPOICA), and all the institutions participating in the LTACs across Latin America.

\section{References}

Loboguerrero AM, Boshell F, Leon G, Martinez-Baron D, D, Recaman L, Diaz E, Cock J. (2018). Bridging the glimate Risk Management, 22:67-81. doi:10.1016/j. crm.2018.08.001

CGIAR, CCAFS. (2019). Putting Climate Information in the Hands of Farmers https:///ccafs.cgiar.org/publications/putting
climate-information-hands-farmers XWFNa3dFxYc Climate information hands farmerst.XW Na3drXKC Challinor, A., Müller, C., Asseng, S., Deva, C., Nicklin, K., J., Koehler, A. (2018) Improving the use of crop models for risk assessment and climate change adaptation'. Agricultural Systems, Vol.159, pp. 296-306.

Esquivel, A., Llanos-Herrera, L, Agudelo, D., Prager, S., Fernandes, K., Rojas, A., Valencia, J., and Ramirez-Villegas, J. (2018). Predictability of seasonal precipitation across major crop growing areas in Colombia. Climate Senvices, Vol. 12 ,
pp. $36-47$.

\section{Personal Response}

How relevant do you think the role of LTACs will be in the coming years given the soverty of expected

II Climate change is already increasing the intensity and frequency of extreme events such as floods and draughts. these drastic changesin weather conditions. Putting climate information combined with crop modelling analysis in the hands of farmers has the potential to become a gan changer for reducing losses associated with climate events. Furthermore, farmers have the ability to respond to climate challenges if they actively participate in the definition of key strategy to protect the livelihoods of millions of farmers
around the world.

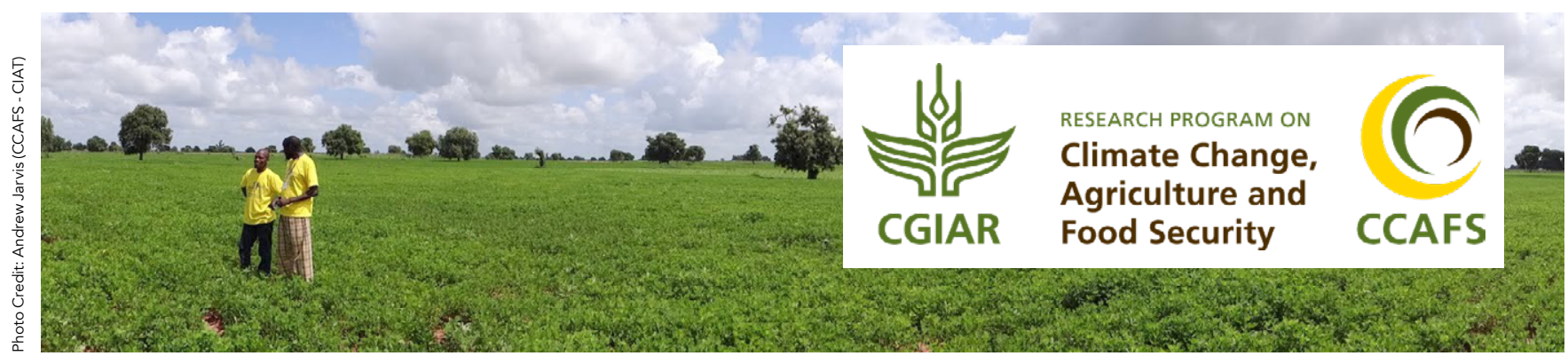

